\title{
Polyurethane Green Composites: Synthesize, Characterization and Treatment of Boron Present in the Oil Produced Water
}

\author{
Murtuza Ali Syed ${ }^{1 *}$, Mohammed Al Sawafi ${ }^{1}$, Feroz Shaik ${ }^{2}$, Mohammed Nayeemuddin ${ }^{2}$ \\ ${ }^{1}$ National University of Science and Technology, Muscat, Sultanate of Oman. \\ ${ }^{2}$ Prince Mohammad Bin Fahd University, Al Khobar, Kingdom of Saudi Arabia. \\ *Correspondence to: Murtuza Ali Syed \\ ORCIDs: 0000-0003-2398-3436 (Dr. Syed Murtuza Ali), 0000-0002-9174-4819 (Dr. Feroz Shaik)
}

\begin{abstract}
Polyurethane (PU) based algae biocomposite is synthesized, characterized and tested for boron removal from oil produced water (OPW). The percentage of algae is varied in the biocomposite and its physical and chemical properties are evaluated. The surface morphology, crystalline structure, thermal stability is characterized using scanning electron microscope (SEM), Fourier transform infrared spectroscopy (FITR) and thermal gravimetric analysis (TGA). The density of synthesized PU/algae composites is in the range of 1.12 and $1.20 \mathrm{~g} / \mathrm{mL}$ based on content of filler in the PU matrix. Weight losses of the tested specimens in various chemical solutions are less than $10 \%$. The boron removal efficiency is in the range of 84 to $85 \%$, depending upon the algae filler at $\mathrm{pH} 7.19$.
\end{abstract}

Keywords: Polyurethane, Green composites, Oil produced water, Boron, PU/algae.

\section{INTRODUCTION}

The combination of biomaterials with synthetic polymers is a good alternative to traditional products. This biocomposite will address the pertaining environmental and social issues in today's life [1.2]. It is a great advantage that abundant available biomaterial such as algae can be utilized to produce valuable polyurethane polymer composite. Using algae as filler is having many advantages. Low cost, renewability, environmental friendly, non-toxic, high strength and low density [3,4]. Jutefiber-reinforced green composites based on Mesua ferrea L. are prepared with poly (urethane ester) and poly (urethane amide) resin blends with commercially available partially butylated melamine-formaldehyde and epoxy resins through solution impregnation and hot-curing methods. The water uptake in different chemical media is observed, and found that all of the composites possessed excellent hydrolytic stability against almost all of the media except the alkali. Thermogravimetric analysis (TGA) of the composites showed degradation much above that of the virgin blends, which indicated their high thermostability [5].

A series of polyurethane (PU) green composites are synthesized with varying amounts, viz. $0,2,4,8$, and $12 \mathrm{wt} \%$ of soya protein isolate (SPI). Formation of the urethane linkage in the prepared green composites is revealed by infrared spectroscopy. TGA thermograms clearly revealed that the fabricated composites were thermally stable upto $181^{\circ} \mathrm{C}$ and show a three- step of thermal degradation [6]. Indian butter tree seed waste (mahua seed cake [MSC]) is sued as filler and a series of PU composites have been fabricated with varying amounts, namely, $0,2.5,5.0,7.5$, and $10 \mathrm{wt} \%$, of MSC. It was found that the tensile strength of the green composites increased from 5.61 to $9.5 \mathrm{MPa}$ and tensile modulus increased from 4.75 to $6.07 \mathrm{MPa}$ with an increase in filler content from 2.5 to $7.5 \mathrm{wt} \%$ [7].

Oil industry worldwide produces large amounts of oil produced water (OPW). OPW accompanies with crude oil during the production process. OPW is highly saline with suspended solids, organic compounds, heavy metals, microorganisms and dispersed oil droplets [8]. The disposal of OPW is a big challenging task for oil producing companies. Treat and reuse of OPW is viable option other than injection to the oil wells in an enhanced oil recovery process [9]. The treatment of OPW is necessary due to the large amounts that are generated during the production of crude oil and its environmental impacts on discharge, which includes biological effects on marine pelagic ecosystems, causing: endocrine, non-endocrine and reproductive problems [10].

Boron is one of the major chemical contaminant in OPW [11]. The $\mathrm{pH}$ of OPW is generally ranges between 6-8.5 and concentration of born in OPW is about 26-28 ppm [12]. The presence of boron in water affects the reproducibility of living organisms [13]. When water with high boron concentration is used for irrigation, boron compounds form complexes with heavy metals like $\mathrm{Pb}, \mathrm{Cu}, \mathrm{Co}, \mathrm{Ni}, \mathrm{Cd}$ etc. and increase the potential toxicity of these heavy metals. These metal complexes create serious health issues [1416]. Long term ingestion of high boron contaminated water can lead to the impairment of some organ systems of humans and animals; composition of blood changes, children become physically and intellectually challenged, and risk of low birth increases [17]. Treatment of boron in water and wastewater systems is a bit tedious [18]. The treated OPW for reuse should follow WHO standards of $0.5 \mathrm{mg} / \mathrm{L}$ [19]. Various methods include reverse osmosis, adsorption, ion exchange, electro dialysis, electrocoagulation, and coprecipitation applied for the removal of boron from aqueous systems [20-26]. 
International Journal of Engineering Research and Technology. ISSN 0974-3154, Volume 13, Number 8 (2020), pp. 1866-1873

(C) International Research Publication House. https://dx.doi.org/10.37624/IJERT/13.8.2020.1866-1873

Very few studies are reported in the literature for removal of born from OPW. Synthetic wastewater is prepared simulating the range of boron concentrations in produced water. Four operating parameters $\mathrm{pH}$ (3-11), charge loading (1200$\left.3600 \mathrm{Ah} / \mathrm{m}^{3}\right)$, contact time (15-90 $\left.\mathrm{min}\right)$ and concentration $(10$ $30 \mathrm{mg} / \mathrm{L})$ are selected and their optimum conditions investigated through electrocoagulation process [27]. Various studies reported on the usage of polymer composites for the removal of boron from aqueous solutions. Boron removal is evaluated by using calcium alginate beads (CA) and a novel alginate-alumina (CAAl) as sorbents in a batch system. The eff ects of different parameters such as $\mathrm{pH}$, temperature, contact time, and composition of alginate (at diff erent concentrations of guluronic and mannuronic acids) on boron sorption are investigated. The results confirm that calcium alginate beads (CA) exhibited a better adsorption capacity in a slightly basic medium, and the composite alginate-alumina (CAAl) exhibited improved boron removal at neutral $\mathrm{pH}$ [28]. Boron removal from water using zero-valent iron nanoparticles (nZVI) stabilized by two biopolymers is analyzed. Modified nZVI is synthesized using the method of ferrous sulfate reduction. The function of $\mathrm{S}-\mathrm{nZVI}$ in boron removal is examined under the influence of various factors including initial concentration of boron, S-nZVI dose, $\mathrm{pH}$, and contact time in batch conditions. The results showed that $1 \mathrm{mg} / \mathrm{L}$ of $\mathrm{S}-$ nZVI can reduce up to $20 \mathrm{mg} / \mathrm{L}$ of boron to less than its maximum allowable concentration in the $\mathrm{pH}$ of 8.5 and reaction time of $90 \mathrm{~min}$ [29]. A chitosan hydrogel supported with ceria (labelled Ce-CTS) is prepared by an encapsulation technique and used for the efficient removal of excess B(III) from aqueous solutions. The results demonstrated that $\mathrm{Ce}-\mathrm{CTS}$ removes boric acid from aqueous solutions more efficiently than either ceriumdioxidehydrate or raw chitosan beads, the precursors of the Ce-CTS biosorbent. The maximum adsorption capacity of $13.5 \pm 0.9 \mathrm{mg} / \mathrm{g}$ is achieved at $\mathrm{pH} 7$ after $24 \mathrm{~h} \mathrm{[30].} \mathrm{In} \mathrm{the} \mathrm{present}$ research, an attempt is made to treat boron present in the oil produced water with synthesized polyurethane algae based biocomposite. This is first time a polyurethane algae based biocomposite is used as adsorbent for the treatment of boron present in OPW. The performance of adding the algae additives on PU properties is studied with different mass ratios. The characterization of the formed PU polymer with different algae composition is carried out to estimate the effects of amount of filler content on the density, chemical resistivity, crystalline structure and thermal stability.

\section{EXPERIMENTAL}

\subsection{Materials and methods}

Tolylene 2,4 Diisocyanates (TDI) of analytical grade (95\%), Dibutyltin dilaurate (DLDBT), Methyl isobutyl ketone (MIBK) is purchased from Sigma- Aldrich, Germany. Castor oil (CO) is procured from local markets. Castor oil is the only natural oil polyol available in the market, which is produced directly from a plant sources without any chemical modifications. An alga is extracted from the sea rack, which is glued to the rock surface. The algae is dried and crushed into powder form. Before mixing algae with polymer, it was screened by sieve mesh size 300 micro to get uniform particle size. The filler density is estimated as $1.27 \mathrm{~g} / \mathrm{ml}$. All other analytical grade reagents are procured from local market and used as pure as supplied.

\subsection{Synthesis of PU/Algae biocomposites}

$50 \mathrm{ml}$ of methyl iso butyl ketone (MIBK) solvent is placed in the necked round bottom flask. Calculated amounts of tolylene 2,4 disocyanates (TDI), castor oil (CO) and 3 drops of catalyst dibutyltin dilaurate (DLDBT) are added to MIBK solvent as per standard procedure [6,7]. The flask is then kept on digital hot plate fitted with a condenser. The temperature is maintained between $60-70^{\circ} \mathrm{C}$ and stirred at $1200 \mathrm{RPM}$. The reaction between the aromatic TDI isocyanates, which is having two isocyanates groups $(\mathrm{NCO})$ and a hydroxyl group (present in the castor oil) in the presence of catalyst DLDBT produce urethane groups as showed in the equation $1[6,7]$.

$$
\mathrm{ROH}+\mathrm{R}^{\prime} \mathrm{NCO} \rightarrow \operatorname{ROC}(\mathrm{O}) \mathrm{N}(\mathrm{H}) \mathrm{R}^{\prime}
$$

The algae powder is added to the PU solution after 30 minutes of mixing with different polymer-algae weight ratios $(100 / 0$, 97.5/2.5, 95/5, 92.5/7.5 and 90/10). PU/algae is stirred again for 1 hour. The resulting viscous solution poured into a clean glass mold of dimension of $20 \times 10 \times 4 \mathrm{~cm}$ to get the uniform polymer film. The solution is cooled and dried slowly under ambient temperature overnight. The created PU sheet in the glass mold has been post cured in the electric oven at $60^{\circ} \mathrm{C}$ for 5 hours. The prepared biocomposite sheets are taken out and stored for characterization and experimentations.

\subsection{Collection of OPW}

Oil Produced water (OPW) is collected from (Oxy-Oman) site (Makizina) for this experimental purpose. Mukhaizna field is located in Oman's south central interior and it is producing very high viscosity oil. The initial boron and other multi component concentrations are estimated using Shimadzu model 9000 plasma atomic emission spectrometry (ICP-AES). The initial boron concentration in the produced water is obtained as 6.44 $\mathrm{mg} / \mathrm{L}$. The initial $\mathrm{pH}$ value of OPW sample is measured as 7.19.

\subsection{PU/Algae Characterization}

ASTM D792-08 method is used to determine the experimental density of the specimens. The weight of the specimen is taken in the air and in immersed water at room temperature to determine the specific gravity. Accordingly calculated the density of PU/Algae polymer specimens. The theoretical density is calculated for the composites by the weight additive principle as shown in equation $2[6,7]$.

$\rho=\omega_{1} \rho_{1}+\omega_{2} \rho_{2}$

Where $\rho$ is the density of composite, $\omega_{1}, \rho_{1}, \omega_{2}, \rho_{2}$ are the weight fraction, the density of the filler and neat polymer respectively.

The chemical resistance of PU/Algae polymer composites is studied in the various chemical reagents such as acids, basis, salts and organic solvents. Uniform surface area of PU/Algae composites is taken and immersed in the prepared chemical solutions for 7 days under laboratory environment. After 7 
days, the specimens are removed and wiped with tissue papers and weighted. Then, the percentage weight changes are calculated. Also, surface to mass of the specimens are estimated. The morphological behavior, chemical composition and crystalline structure of the PU/algae composites is investigated by using Jeol model JSM-7500F scanning electron microscopy (SEM) technique with an operating voltage of 15 $\mathrm{kV}$, magnification of $1000 \mathrm{x}$ and quality resolution of 10 microns. Perkin Elmer spectrum FTIR spectroscopy is used to analyze the physiochemical properties of synthesized PU/Algae composites as per standard procedure in the range of wave number 600 to $4000 \mathrm{~cm}^{-1}$ [31].

A thermal property of polymer is investigated by using thermal gravimetric analysis (TGA) using SDT Q600 V20.9 Build 20 TA instrument in order to determine the test conditions and the behavior of the polymer with increasing temperature. The sample is cut into a small piece and after that loaded into sample ceramics pan to complete thermal analysis. The nitrogen gas grade 5 is used as purge gas and it is supplied at a constant flow rate $100 \mathrm{ml} / \mathrm{min}$. The thermal analysis in TGA is started in the temperature range between 32 and $38^{\circ} \mathrm{C}$ and the final temperature considered for this analysis is $800^{\circ} \mathrm{C}$. The heating rate is customized at $10^{\circ} \mathrm{C} / \mathrm{min}$. The thermograms are interpreted for all composites by using TA instrument explorer software universal V4.7A.

\subsection{Boron adsorption characteristics}

The treated oil produced water (OPW) is analyzed to examine the boron adsorption efficiency for different PU/algae composites. The adsorbent dosage is fixed as $1 \mathrm{~g}$ in $50 \mathrm{~mL}$ of OPW for all PU compositions. The agitation is adjusted at 100 RPM to assist the contact between adsorbent and the untreated OPW for $72 \mathrm{hrs}$. The adsorption process is very slow and reached the optimum values after 72 hours. The final boron concentration is obtained using plasma atomic emission spectrometry (ICP) and then the removal efficiencies are estimated.

\section{RESULTS AND DISCUSSION}

\subsection{Physical Properties}

Three specimens are taken from each sample to determine the average density of PU/Algae compositions. The changes in density in a single polymer sheet are due to localized differences in crystalline structure, loss of plasticizer, absorption of methyl iso butyl ketone solvent and differences in algae filler compositions. The densities of neat polymer and algae filler estimated as 1.124 and $1.27 \mathrm{~g} / \mathrm{mL}$ respectively. Both theoretical and experimental values for the PU/algae green composites is estimated and tabulated in Table 1 . The densities estimated are in the range of 1.12 and $1.20 \mathrm{~g} / \mathrm{mL}$ based on the content of the filler in the PU matrix. The density increased with an increase of the filler in green composite. This may be due to the restriction of soft PU to pass through the tiny space between the rigid filler particles. The experimental results are slightly higher than theoretical results. This is due to the aggregation of filler at its higher content and maybe the filler not wetted completely in the PU matrix [6,7]. The surface area of the uniform mass of specimens is decreased with an increase in the filler content. This may be due to the passage of the high density filler into the gaps of the PU matrix. Hence, the higher filler content polymer has less surface area compared to the analogous mass of less filler content polymer.

Table 1. Physical properties of PU/algae composite

\begin{tabular}{|c|c|c|c|c|}
\hline \multirow{2}{*}{$\begin{array}{c}\text { PU/algae } \\
\text { compositions }\end{array}$} & \multicolumn{2}{|c|}{ Density (g/ml) } & \multirow{2}{\text{Void}}{$\begin{array}{c}\text { Surface to } \\
\text { content } \\
(\%)\end{array}$} & $\begin{array}{c}\text { Experimental } \\
\text { mass of the } \\
\text { specimens } \\
\left(\mathbf{c m}^{2} / \mathbf{g}\right)\end{array}$ \\
\hline $100 / 0$ & 1.122188 & 1.122188 & 0 & 31.25 \\
\hline $97.5 / 2.5$ & 1.126353 & 1.125883 & 0.0004 & 26.67 \\
\hline $95 / 5$ & 1.162581 & 1.129578 & 0.0284 & 24.09 \\
\hline $92.5 / 7.5$ & 1.206 & 1.133273 & 0.0603 & 21.86 \\
\hline $90 / 10$ & 1.208182 & 1.136969 & 0.0589 & 21.16 \\
\hline
\end{tabular}

\subsection{Chemical Resistivity}

The chemical resistivity of synthesized PU/algae polymer composites is studied in the various chemical reagents. The chemical resistivity study helps to understand, the applicable uses of the PU/algae. It shows to what extent the algae powder can stay in touch with the PU specimen under various chemical environments. The weight losses for different PU/Algae specimens are obtained after 7 days are shown in Table 2. The percentage weight losses of the tested samples in the various chemical agents are within acceptable limit, which is less than $10 \%$ [6,7]. Furthermore, it is observed that PU/algae composites are dissolved rapidly in the acidic and basic solution than other chemical solutions. There is no significant change in surface color and thickness of the PU/algae specimens in the various tested chemical solutions.

Table 2. Chemical resistivity of PU/algae composites

\begin{tabular}{|c|c|c|c|c|c|}
\hline \multirow[b]{2}{*}{$\begin{array}{l}\text { Chemical } \\
\text { Reagent }\end{array}$} & \multicolumn{5}{|c|}{ \% Weight Loss for PU/algae Composition } \\
\hline & $100 / 0$ & $97.5 / 2.5$ & $95 / 5$ & $92.5 / 7.5$ & 90/10 \\
\hline $\begin{array}{l}5 \% \text { Sodium } \\
\mathrm{Hydroxide,} \\
\mathrm{NaOH}\end{array}$ & 2.87 & 5.24 & 4.0 & 7.73 & 6.55 \\
\hline $\begin{array}{l}5 \% \text { Sulfuric } \\
\text { Acid, } \mathrm{H}_{2} \mathrm{SO}_{4}\end{array}$ & 1.98 & 5.65 & 4.96 & 6.50 & 6.31 \\
\hline $\begin{array}{l}5 \% \text { Ethanol, } \\
\mathrm{C}_{2} \mathrm{H}_{6} \mathrm{O}\end{array}$ & 0.5 & 2.13 & 2.69 & 1.42 & 1.92 \\
\hline $\begin{array}{l}5 \% \text { Methanol, } \\
\mathrm{CH}_{3} \mathrm{OH}\end{array}$ & 1.08 & 2.47 & 0.65 & 1.05 & 1.87 \\
\hline $\begin{array}{l}5 \% \text { Sodium } \\
\text { Carbonate, } \\
\mathrm{Na}_{2} \mathrm{CO}_{3}\end{array}$ & 0.18 & 0.25 & 0.30 & 0.55 & 0.21 \\
\hline
\end{tabular}


International Journal of Engineering Research and Technology. ISSN 0974-3154, Volume 13, Number 8 (2020), pp. 1866-1873

(C) International Research Publication House. https://dx.doi.org/10.37624/IJERT/13.8.2020.1866-1873

\subsection{Surface Morphology}

The SEM images of different PU/algae composites are shown in Figures 1(A)-1(E). SEM images indicate that algae powder have been distributed and integrated properly in the PU matrix. The 5\% of filler weight in the PU matrix (Figure 1C) is distributed uniformly compared to the other filler composites. All the SEM images shown good adhesion of the filler into PU matrix. It is observed, the roughness and deformation of the polymers increased with an increase of the algae filler content. It may be due to the restriction of soft PU to pass through the tiny space between the rigid filler particles $[6,7]$.
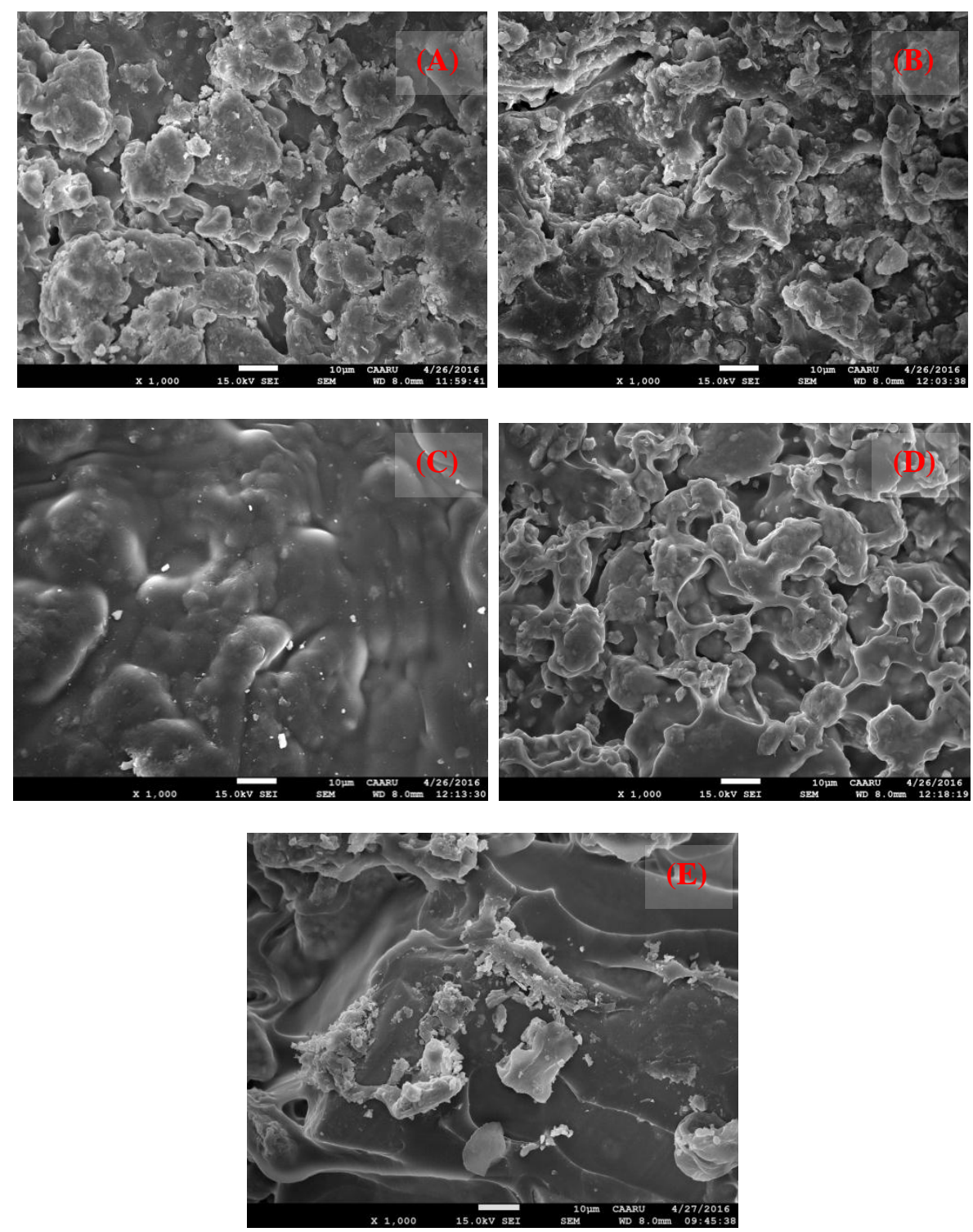

Figure 1. SEM images of PU green composites with

(A) $0 \%$, , B) $2.5 \%$, (C) $5 \%$, (D) $7.5 \%$ and (E) $10 \%$ of algae filler

\subsection{FTIR Studies}

FTIR spectra of PU/algae composites are shown in Figure 2. Most of the synthesized biocomposite polymers shown the absence of the peak between 2270 and $2280 \mathrm{~cm}^{-1}$ indicating that no free NCO groups [32]. All the isocyanate groups have reacted during the polymerization process. Furthermore, $\mathrm{NCO}$ group peak areas are increased slightly with an increase of algae mass ratio. This indicates the reactivity of urethane NCO group decreased with an increase in the algae green composition. $\mathrm{OH}$ group peaks are not observed for all the developed polymer composites as shown in the Figure 2. Complete reaction of $\mathrm{OH}$ group with isocyantes groups. It is also observed absence of Urethane $-\mathrm{C}=\mathrm{O}$ vibration in the range of $1720-1730 \mathrm{~cm}^{-1}$ for the $7.5 \%$ algae content and appearance of $\mathrm{C}=\mathrm{C}$ aromatic vibration in the all the synthesized PU/algae composites. Table 3 illustrates the expected range of the peaks of FT-IR spectra of PU/Algae composites and the observed peaks from the estimated curves. 
International Journal of Engineering Research and Technology. ISSN 0974-3154, Volume 13, Number 8 (2020), pp. 1866-1873

(C) International Research Publication House. https://dx.doi.org/10.37624/IJERT/13.8.2020.1866-1873

Table 3. FTIR spectroscopy peaks of PU/algae composites

\begin{tabular}{|l|l|l|l|l|l|l|}
\hline \multirow{2}{*}{ Group } & \multirow{2}{*}{ Expected Peak $\left(\mathrm{cm}^{-1}\right)$} & \multicolumn{2}{l}{ Observed Peak $\left(\mathrm{cm}^{-1}\right)$} \\
\cline { 3 - 7 } & & 0 & 2.5 & 5 & 7.5 & 10 \\
\hline NCO Vibration & $2270-2280$ & None & None & None & None & None \\
\hline C=O Vibration & $1700-1750$ & 1726 & 1725 & 1726 & 1701 & 1726 \\
\hline Urethane-C=O Vibration & $1720-1730$ & 1726 & 1725 & 1726 & None & 1726 \\
\hline C=C aromatic Vibration & $1520-1600$ & 1533 & 1533 & 1533 & 1528 & 1530 \\
\hline C-H stretching & $2840-3000$ & 2922 & 2923 & 2923 & 2922 & 2923 \\
\hline OH vibration & $3530-3550$ & None & None & None & None & None \\
\hline
\end{tabular}

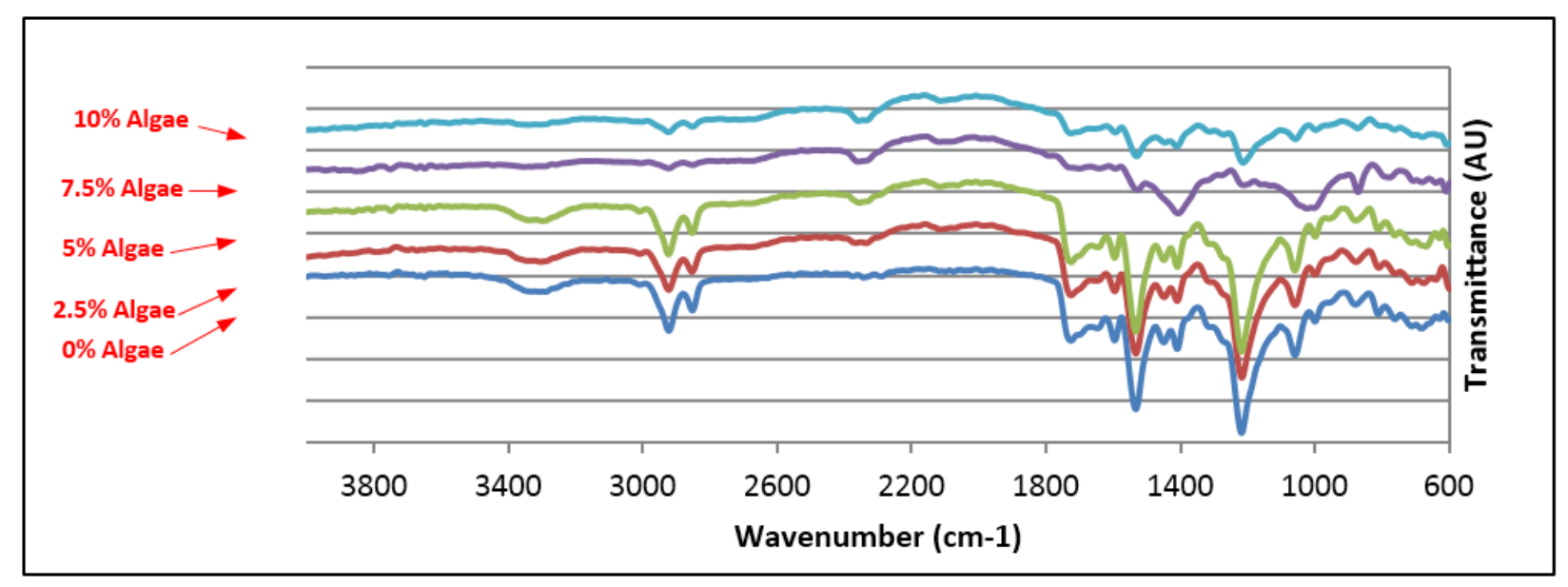

Figure 2. FTIR Spectra of PU/algae Composites

\subsection{Thermogravimetric analysis}

TGA is used to estimate the thermal stability of the PU/algae composites. The obtained thermograms are shown in Figure 3. The TGA thermograms indicated that PU matrix with different mass content of algae are stable up to $70-75^{\circ} \mathrm{C}$. The PU/algae composite degradation can be described in three stages. First stage at temperature range of $75-251.80^{\circ} \mathrm{C}$, the sample loses about $5.29 \%$ of its initial weight due to the gradual evaporation of the methyl iso butyl ketone solvent and the slight degradation of the soft segment in the PU/algae composite. Second stage at temperature range of $251.80-520^{\circ} \mathrm{C}$, the sample losses about $88.46 \%$ of its weight attributed to thermal degradation of the hard segment and partially degradation of the algae component. Finally, the third stage starting at temperature $520^{\circ} \mathrm{C}$ up to upper limit temperature considered for this study $\left(800^{\circ} \mathrm{C}\right)$, the sample loses about $2.14 \%$ of total weight due to decomposition of the algae composite and degradation of the remains hard segment and other associated compartments. More algae content has less weight loss, which indicates that algae can act as good filler for thermal degradation stability of PU polymer.

The relative thermal stability of the PU matrix with different algae content is estimated by comparing the decomposition temperatures at different weight loss percentages as shown in
Table 4. The T0 is expressing the temperature of onset decomposing, whereas T10, T20, T50 and T70 expressing the decomposition temperature at 10, 20, 50, 70 weight loss percentage. The temperature of degradation of PU/algae composites is increased with an increase of algae content at different weight loss percentages. This lead to conclude that filler content is improving the relative thermal stability of the PU polymer. It can be act as a thermal insulator due the ability to block the volatile component during the thermal degradation analysis process.

Table 4. Effect of algae filler on the thermal stability of the PU matrix

\begin{tabular}{|c|c|c|c|c|c|c|}
\hline \multirow{2}{*}{$\begin{array}{l}\text { Algae } \\
\text { content in } \\
\text { PU } \\
\text { matrix }\end{array}$} & \multirow{2}{*}{$\begin{array}{l}\text { Sample } \\
\text { weight } \\
\text { (mg) }\end{array}$} & \multicolumn{5}{|c|}{$\begin{array}{l}\text { Temperature at different weight } \\
\text { losses }\end{array}$} \\
\hline & & $\mathrm{T}_{0}$ & $\mathrm{~T}_{10}$ & $\mathrm{~T}_{20}$ & $\mathrm{~T}_{50}$ & $\mathrm{~T}_{70}$ \\
\hline 0 & 24.775 & 70 & 278 & 298 & 382 & 438 \\
\hline 2.5 & 24.593 & 71 & 278 & 297 & 378 & 437 \\
\hline 5 & 27.81 & 73 & 278 & 299 & 383 & 440 \\
\hline 7.5 & 23.785 & 74 & 280 & 300 & 386 & 442 \\
\hline 10 & 23.474 & 75 & 280 & 301 & 386 & 443 \\
\hline
\end{tabular}




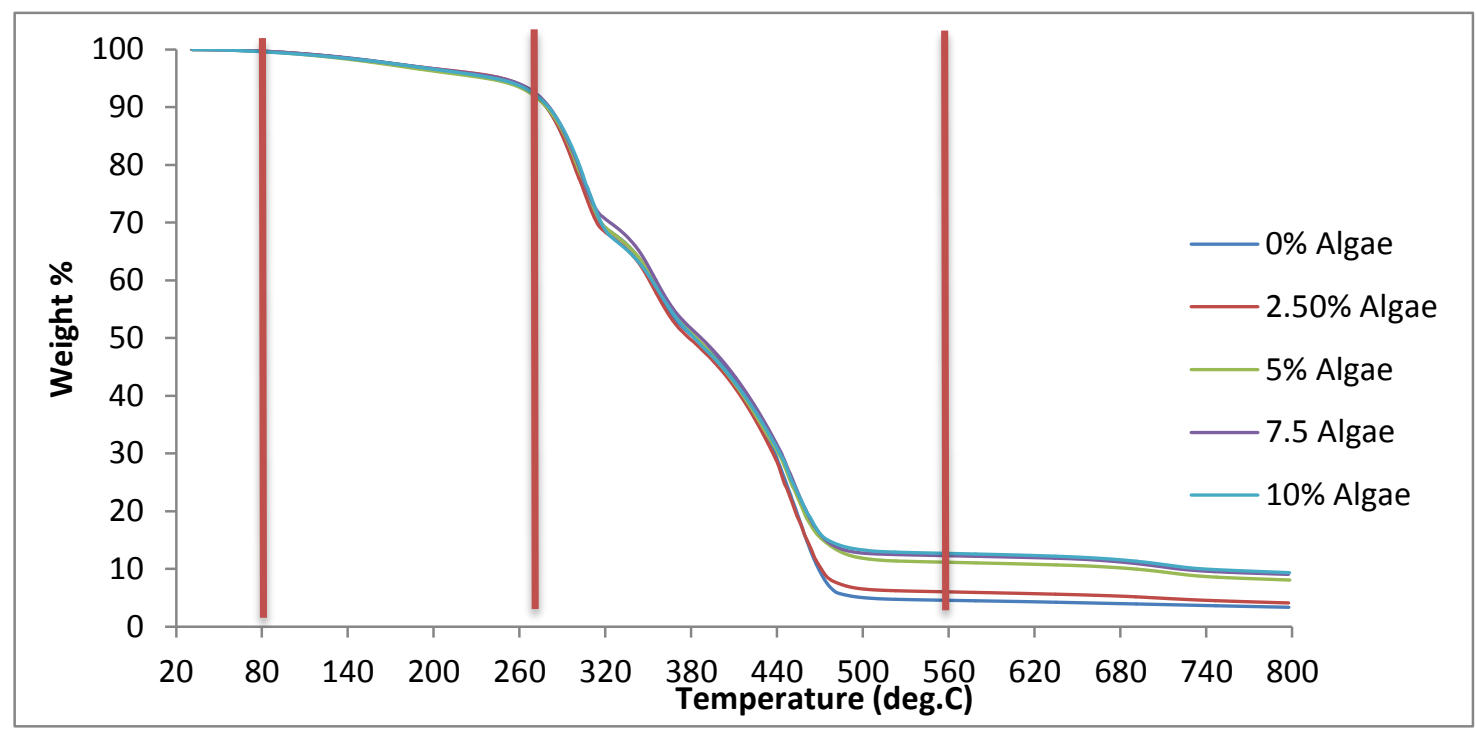

Figure 3. Thermograms of PU/algae composities

\subsection{Boron adsorption studies}

The boron removal from OPW is estimated for different PU/algae composites after 72 hours of contact time. The percentage removal efficiency was estimated using equation 3 [32].

Percentage removal efficiency $=\frac{\left(C_{o}-C_{f}\right)}{C_{o}} \times 100$

Where, $\mathrm{c}_{0}$ and $\mathrm{c}_{\mathrm{f}}$ are the initial and final concentrations in $\mathrm{mg} / \mathrm{L}$ respectively.
The removal efficiency is in the range of 84 to $85 \%$ as shown Figure 4. The maximum boron removal efficiency is observed in case of neat PU polymer as adsorbent due to absence of filler and availability of space between PU matrix molecules. However, there is not much difference between the different PU/algae composites for boron removal efficiency. It was observed that the adsorption process is very slow and took 72 hours to reach the optimum values.

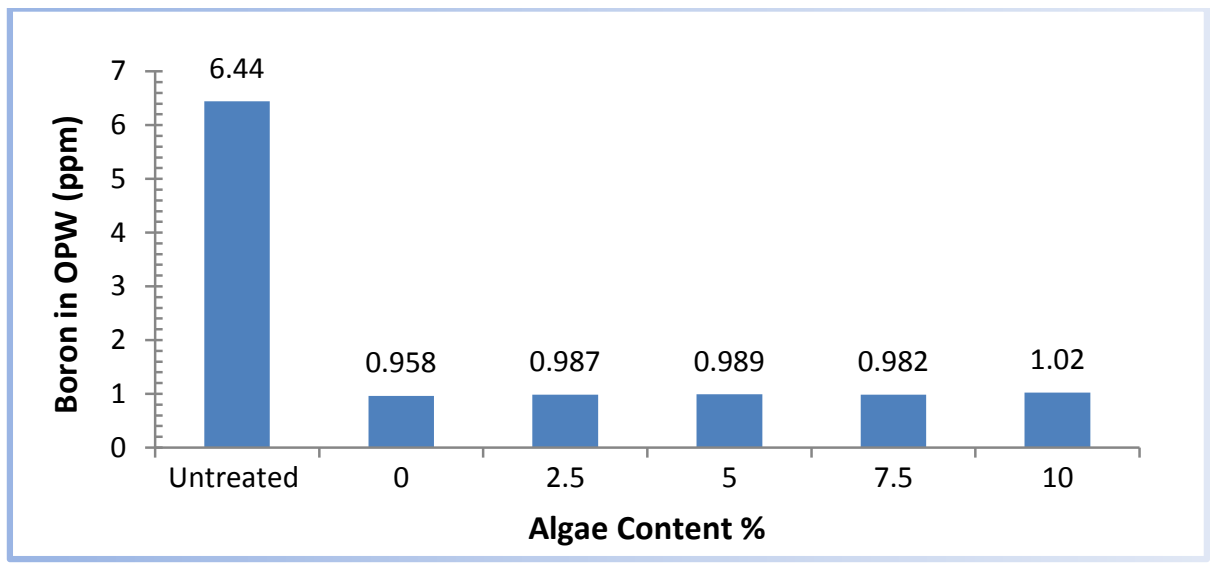

Figure 4. Boron content in OPW after adsorption on PU/algae composites

\section{CONCLUSIONS}

This study investigated the performance of algae based PU polymer composites for the treatment of boron presence in oil produced water (OPW). PU/algae composites synthesized by varying the content of filler algae and their physical and chemical properties are estimated. The density of PU/algae composites is in the range of 1.12 and $1.20 \mathrm{~g} / \mathrm{ml}$ based on content of filler. The density increases with an increase in algae content. The surface area decreased with an increase in the filler content of the uniform mass of PU/algae composites. Weight loss of the tested specimens in various chemical solutions are less than $10 \%$, indicated stable chemical resistance by PU/algae biocomposites. SEM images showed the proper distribution and integration of algae filler in PU matrix. The roughness and difficulty for deformation increases with filler content. FTIR 
spectroscopy indicates the absence of NCO peaks which indicates there is no free $\mathrm{NCO}$ group in the formed polymers. Thermogravimetric analysis showed with increases in filler content, the thermal stability increased. The boron removal efficiency is found to be in the range of $84 \%$ and $85 \%$ at $\mathrm{pH}$ 7.19 .

\section{REFERENCES}

[1] Murtuza, A. S., Siddaramaiah., Raihan, T.S., Akheel. A. S. 2010. Investigation on physico-mechanical properties, water, thermal and chemical ageing of unsaturated polyester/turmeric spent composites, Polymer-Plastics Technology and Engineering. 49(6):555-559.

[2] Murtuza, A. S. Akheel, A. S. 2012, Development of a new inexpensive green thermoplastic composite and evaluation of its physic-mechanical and wear properties, Materials \& Design. 36: 421-427.

[3] Tamara Calvo-Correas., Nagore Gabilondo., Ana Alonso-Varona., Teodoro Palomares., Angeles Corcuera, M., Arantxa Eceiza. 2016. Shape-memory properties of crosslinked biobased polyurethanes, European Polymer Journal. 78:253-263.

[4] Ciecierska, E., Jurczyk-Kowalska, M., Bazarnik, P., Gloc, M., Kulesza, M., Kowalski, M., Krauze, S., Lewandowska, M. 2016, Flammability, mechanical properties and structure of rigid polyurethane foams with different types of carbon reinforcing materials, Composite Structures. 140:67-76.

[5] Suvangshu Dutta, Sasidhar Baruah and Niranjan Karak, 2010. Jute Fiber-Reinforced Polyurethane Green composites based on Mesua ferrea L. seed oil, Journal of applied polymer science, 115(2):843-850.

[6] Madhukar, B.S., Bhadre Gowda, D. G., Hemalatha, K, Somashekar, R., Siddaramaiah, 2018. Polyuretahne/soya protein isolate green composites: Spectral, microstructural, thermal, swelling and biodegradation behaviors, Advances in polymer technology, 37(2): 399-410.

[7] Madhukar, B. S., Bhadre Gowda,D. G., Siddaramaiah., Somashekar, R. 2015. Evaluation of mechanical, thermal, and morphological behaviors of polyurethane/mahua seed cake green composite, Advances in Polymer Technology. 36(2):186-195.

[8] Judd, S., Qiblawey, H., Al-Marri, M., Clarkin, C., Watson, S., Ahmed, A., Bach, S. 2014. The size and performance of offshore produced water oil-removal technologies for reinjection. Separation and Purification Technology 134, 241- 246.

[9] Feroz, S., Khalid Al Saadi., Nageswara Rao, L., Varghese, M. 2017. Performance studies on solar photocatalysis and photo fenton process in treatment of polymer-based oil produced water, International Journal of Photochemistry. 3:1-6.

[10] Bakke, T., Klungsøyr, J., Sanni, S., 2013. Environmental impacts of Produced Water and Drilling Waste Discharges from the Norwegian Offshore Petroleum Industry. Marine Environmental Reasearch 92, 154-169.
[11] Ezerie, H. E., Mohamed, H. I., Shamsul, R. B. M. K. 2012. Boron in produced water: challenges and improvements: A comprehensive review, Journal of applied sciences. 12(5):402-415.

[12] Cakmakce, M., N. Kayaalp and I. Koyuncu, 2008. Desalination of produced water from oil production fields by membrane processes. Desalination, 222:176-186.

[13] Dydo, P., M. Turek, J. Ciba, J. Trojanowska and J. Kluczka, 2005. Boron removal from landfill leachate by means of nanofiltration and reverse osmosis. Desalination, 185: 131-137

[14] Sayiner, G., F. Kandemirli and A. Dimoglo, 2008. Evaluation of boron removal by electrocoagulation using iron and aluminum electrodes. Desalination, 230: 205-212.

[15] Seki, Y., S. Seyhan and M. Yurdakoc, 2006. Removal of boron from aqueous solution by adsorption on $\mathrm{Al}_{2} \mathrm{O}_{3}$ based materials using full factorial design. J. Hazard. Mater., 138: 60-66.

[16] Seyhan, S., Y. Seki, M. Yurdakoc and M. Merdivan, 2007. Application of iron-rich natural clays in Camlica, Turkey for boron sorption from water and its determination by flourimetricazomethine-H method. J. Hazard. Mater., 146: 180-185.

[17] Bryjak, M., Wolska, J., Kabay, N., 2008. Removal of boron from seawater by adsorptionmembrane hybrid process: implementation and challenges. Desalination 223: 57-62.

[18] Bick, A., Oron, G. 2005. Post-treatment design of seawater reverse osmosis plants; boron removal technology selection of potable water production and environmental control, Desalination. 178:233-246.

[19] Boron in drinking water, WHO Guidelines for drinking water quality, 2011. World Health Organization.

[20] Koseoglu, H., Harman, B. L., Yigit, N. O., Guler, E., Kabay, N., Kitis, M. 2010. The effects of operating conditions on born removal from geothermal waters by membrane processes, Desalination. 258 (1-3): 7278.

[21] Alper, E. Y., Recep, B., Serkan, B., Baybars, A. F., Mehmet, M. K. 2012. Boron removal by means of chemical participation with calcium hydroxide and calcium borate formation, Korean. J. Chem. Eng. 29(10):1382-1387.

[22] Demey, H., Vincent, T., Ruiz, M., Sastre, A. M., Guibal, E. 2013. Development of a new chitosan $/ \mathrm{Ni}(\mathrm{OH})_{2}$-based sorbent for boron removal, Chemical Engineering Journal. 244:576-586.

[23] Ruiz, M., Tobalina, C., Demey-Cedeno, H., BarronZambrano, J. A. Sastre, A. M. 2013. Sorption of boron on calcium alginate gel beads, Reactive Function Polymers. 73:653-657.

[24] Joanna, W. Marek, B. 2013, Methods of boron removal from aqueous solutions, Desalination. 310:18-24.

[25] Melnyk, L., Goncharuk, V., Butnyk, I., Tsapiuk, E. 2005. Boron removal from natural and wastewaters 
International Journal of Engineering Research and Technology. ISSN 0974-3154, Volume 13, Number 8 (2020), pp. 1866-1873

(C) International Research Publication House. https://dx.doi.org/10.37624/IJERT/13.8.2020.1866-1873

using combined sorption membrane process, Desalination. 185:147-157.

[26] Turek, M., Dydo, P., Trojanowska, J., Campen, A. 2007. Adsorption/Co-precipitation-reverse osmosis system for boron removal, Desalination. 205:192-199.

[27] Ezerie Henry Ezechi., Mohamed Hasnain Isa., Shamsul Rahman Mohamed Kutty., Asim Yaqub. 2014. Boron removal from produced water using electrocoagulation, Process Safety and Environmental Protection, 92:509-514.

[28] Hary Demey., Jesus Barron-Zambrano., Takoua Mhadhbi., Hafida Miloudi., Zhen Yang., Montserrat Ruiz., Ana Maria Sastre., 2019. Article Boron Removal from Aqueous Solutions by Using a Novel Alginate-Based Sorbent: Comparison with $\mathrm{Al}_{2} \mathrm{O}_{3}$ Particles, Polymers, 11:1509.

[29] Hassan Khorsandia., Aliye Azarnioushb., Ali-Ahmad Aghapoura., Sepideh Nematib., Sima Karimzadehb., Hamid-Reza Khalkhalic H. Khorsandi. 2017. An analysis of boron removal from water using modified zero-valent iron nanoparticles, Desalination and Water Treatment, 70:284-289.

[30] Joanna Kluczka., Gabriela Dudek., Alicja KazekKe`sik., Małgorzata Gnus. 2019. Chitosan Hydrogel Beads Supported with Ceria for Boron Removal, International Journal Molecular Science. 20:1567.

[31] Marek, W. U. 1993. Fourier transform infrared and fourier transform Raman spectroscopy of polymers, Structure-Property Relations in Polymers, Chapter 1: 3-40.

[32] Murtuza Ali, S. and Amit Kumar, M. F. Shaik, 2020. Investigation of epoxy resin/nano- $\mathrm{TiO}_{2}$ composites in photocatalytic degradation of organics present in oilproduced water. International Journal of Environmental Analytical Chemistry. 100: 1-16. 